\title{
Microwave Assisted Synthesis, Modification with Platinum and Photocatalytical Properties of $\mathrm{TiO}_{2}$ Nanofibers
}

\author{
Reinis DRUNKA *, Janis GRABIS, Aija KRUMINA \\ Riga Technical University, Institute of Inorganic Chemistry, Miera 34, Salaspils, LV-2169, Latvia \\ cross $^{\text {ref }}$ http://dx.doi.org/10.5755/j01.ms.22.1.7353
}

Received 16 June 2014; accepted 15 July 2015

In the present work formation of active $\mathrm{TiO}_{2}$ nanoparticles in microwave synthesis and their modification with platinum were studied. Anatase nanopowder and $10 \mathrm{M} \mathrm{KOH}$ solution were used as raw materials. Microwave assisted synthesis method permited to obtain $\mathrm{TiO}_{2}$ nanofibres and nanowires with a diameter of $10 \mathrm{~nm}$ and a specific surface area in the range of $70-150 \mathrm{~m}^{2} / \mathrm{g}$. In order to modify $\mathrm{TiO}_{2}$ nanofibers with platinum it was stirred in $\mathrm{H}_{2} \mathrm{PtCl}_{6}$ solution under UV irradiation. Photocatalytic activity was determined by degradation of the methylene blue (MB) solution under UV and visible light irradiation. The obtained samples showed higher photocatalytic activity with respect to pure $\mathrm{TiO}_{2}$ nanofibers. The doped $\mathrm{TiO}_{2}$ nanofibers were appropriate for degradation of harmful organic compounds as well as for hydrogen production by water splitting.

Keywords: titania nanofibers, nanowires, anatase, platinum, photocatalysis.

\section{INTRODUCTION}

The synthesis of nanotubes has become one of the most important research subjects in nanotechnology and various nanotubular materials have been produced during the last decades [1]. Titania nanotubes, nanowires and nanofibers due to large specific surface area and relatively simple and cost-effective preparation methods are a promising material for photocatalytic decomposition of organic compounds, splitting water and for dye sensitized solar cells $[2,3]$. Many efforts have dedicated to the modification of $\mathrm{TiO}_{2}$ nanoparticles in their morphology and phase structures through various methods, such as the hydrothermal synthesis method, sol-gel, anodization and template method. The microwave-assisted hydrothermal method has unique advantages of uniform and rapid heating in comparison with the conventional one. In addition, this method can significantly reduce the reaction time, leading to the fast crystallization and simplification of the preparation procedure [4]. However titania due to wide band-gap $(3.2 \mathrm{eV})$ exhibits high photocatalytic activity under ultraviolet illumination. Only $5 \%$ from sunlight is UV radiation but about $45 \%$ is visible light. A large number of investigations aimed at increase $\mathrm{TiO}_{2}$ photocatalytic activity under visible light have been carried out over last years. It is established that photocatalytic activity of $\mathrm{TiO}_{2}$ nanoparticles and nanotubes can be increased by doping with nitrogen, sulfur [5,6]. The improved photocatalytic activity of $\mathrm{TiO}_{2}$ nanoparticles and mesoporous films has been achieved by doping with such metal oxide as $\mathrm{WO}_{3}$ [7]. One more promising dopant is platinum $[8-10]$. The short reaction times provided by microwave synthesis make it ideal for rapid reaction

\footnotetext{
* Corresponding author. Tel.:+371-67944711; fax: +371-67800768.

E-mail address: reinis_drunka@inbox.lv(R. Drunka)
}

scouting and optimization of reaction conditions [11]. Although, it is difficult to compare their effectivity for photocatalysis, because conditions of preparation methods differ. The aim of the present work is to determine characteristics of $\mathrm{TiO}_{2}$ nanofibers and nanowires doped with $\mathrm{Pt}$, in dependence on doping agent content and to compare their photocatalytic activity.

\section{EXPERIMENTAL DETAILS}

\subsection{Microwave synthesis of $\mathrm{TiO}_{2}$ nanofibers and nanowires}

The $\mathrm{TiO}_{2}$ samples were prepared by a microwave method similar to hydrothermal method but in shorter reaction time. For this purpose, a certain amount of $\mathrm{TiO}_{2}$ anatase nanopowder (Sigma-Aldrich, $\geq 99.7 \%,<25 \mathrm{~nm}$ particle size) was dissolved in $700 \mathrm{~mL}$ of $10 \mathrm{M} \mathrm{KOH}$ at room temperature. This aqueous solution was poured in to microvave vessel made from teflon. The microwave treatment was performed at $230{ }^{\circ} \mathrm{C}$ for $40 \mathrm{~min}$ by using Anton Paar Masterwave BTR microwave system. Solution was stirred with speed $700 \mathrm{rpm}$ during the reaction time. The as obtained solution was then cooled to room temperature and left to precipitate $\mathrm{TiO}_{2}$ particles. After this procedure, $\mathrm{KOH}$ solution was decanted from vessel and obtained $\mathrm{TiO}_{2}$ suspension was diluted with large amount of deionised water to decrease concentration of $\mathrm{KOH}$. Washing and decanting procedures were repeated several times. Finaly a certain amount $1 \mathrm{M} \mathrm{HCl}$ was added to $\mathrm{TiO}_{2}$ suspensison to reduce $\mathrm{pH}$ to 7.0. Obtained solution was filtered by using $1.0 \mu \mathrm{m}$ cellulose nitrate membrane filter. Particles were washed on filter several times with deionised water and $96 \%$ ethanol. The powder was submitted to drying at $110{ }^{\circ} \mathrm{C}$ for $24 \mathrm{~h}$. After drying $\mathrm{TiO}_{2}$ nanofiber powder was stirred in $1 \mathrm{M} \mathrm{HCl}$ solution for $24 \mathrm{~h}$ to remove titanates. This procedure also allowed to 
decrease absorption process of $\mathrm{MB}$ on $\mathrm{TiO}_{2}$ nanofibers surface.

\section{2. $\mathrm{TiO}_{2}$ nanofiber and nanowire modification with platinum}

$0.0300 \mathrm{~g} \mathrm{H}_{2} \mathrm{PtCl}_{6} \cdot 6 \mathrm{H}_{2} \mathrm{O}$ were dissolved in $100 \mathrm{~mL}$ deionised water and stirred for $5 \mathrm{~min} .1 .00 \mathrm{~g}$ or $0.20 \mathrm{~g} \mathrm{TiO}_{2}$ nanowire powder were added to obtained solution and stirred for $30 \mathrm{~min}$. To modify $\mathrm{TiO}_{2}$ nanofibers with platinum, UV lightsource (FEK-56, $120 \mathrm{~W}$ mercury high presure UV lamp) was used. Solution was transferred into quartz beaker and stirred under UV irradiation for $40 \mathrm{~min}$. The distance from light source to beaker was $11 \mathrm{~m}$. Under UV irradiation $\mathrm{PtCl}_{6}{ }^{2-}$ anions were reduced and $\mathrm{TiO}_{2}$ nanofibers and nanowires were doped with platinum.

After modification suspension was filtred by using $1 \mu \mathrm{m}$ cellulose nitrate membrane filter and was washed with deionised water for several times. The obtained powder was submitted to drying at $110{ }^{\circ} \mathrm{C}$ for $24 \mathrm{~h}$. After drying process $\mathrm{TiO}_{2}$ photocatalyst nanopowder were calcinated at $500{ }^{\circ} \mathrm{C}$ for $2 \mathrm{~h}$ to obtain anatase.

\subsection{Photocatalytic properties}

Photocatalytic properties of the obtained $\mathrm{TiO}_{2}$ nanopowder were tested by using degradation of $\mathrm{MB}$ solution under UV and visible light irradiation. FEK-56, $120 \mathrm{~W}$ mercury high presure UV lamp was used as UV light source and Philips Torndo $23 \mathrm{~W}$ halogen lamp as visible light source. $100 \mathrm{~mL} \mathrm{MB}$ solution $(7,2 \mathrm{mg} / \mathrm{L})$ were poured in quartz beaker and stirred in the dark for $30 \mathrm{~min}$ to control absorbtion process on $\mathrm{TiO}_{2}$ surface. Degradation process of $\mathrm{MB}$ solution was controled by using spectrophotometer Janwey 6300. Absorption of MB solution was measured at wave lenght of $662 \mathrm{~nm}$. As reference with $100 \%$ transmission deionized water was used.

During the experiments every minute suspension samples $(2 \mathrm{ml})$ were taken out and centrifuged to remove nanopowder particles before absorption was measured.

\section{RESULTS AND DISCUSSION}

\subsection{Characterization of physical properties}

Characterization of physical properties such as morphology, crystallization, chemical content, surface areas were done by scanning electron microscopy (SEM), X-ray diffraction (XRD), X-ray fluorescence (XRF), BET surface area analysis methods, respectively.

Specific surface area were obtained by using BET method and HROM 3 gas analyzer. Results of specific surface area measurements are shown in Table 1. As prepared $\mathrm{TiO}_{2}$ nanofibers and nanowires were with extreamly large specific surface $\left(122.6-158.5 \mathrm{~m}^{2} / \mathrm{g}\right)$. Thermal treatment decreased specific surface area down to $125 \mathrm{~m}^{2} / \mathrm{g}$ and down to $85 \mathrm{~m}^{2} / \mathrm{g}$ after $24 \mathrm{~h}$ stirring process at $1 \mathrm{M} \mathrm{HCl}$.

Doped with $\mathrm{Pt} \mathrm{TiO}_{2}$ nanofibers and nanowires were with specific surface area in the range of $70-53 \mathrm{~m}^{2} / \mathrm{g}$ depending on Pt content.

The chemical analysis was done by using X-ray fluorescent spectrometer Bruker Pioneer S4. It was obtained that samples doped with platinum contains $6.27 \%$ and $1.22 \%$ Pt.

Table 1. Comparison of specific surface area of various $\mathrm{TiO}_{2}$ samples

\begin{tabular}{|l|c|}
\hline \multicolumn{1}{|c|}{ Sample } & $\begin{array}{l}\text { Specific surface } \\
\text { area, } \mathrm{m}^{2} / \mathrm{g}\end{array}$ \\
\hline Pure $\mathrm{TiO}_{2}$ nanopowder (comercial) & 98.2 \\
\hline Pure $\mathrm{TiO}_{2}$ nanofibers and nanowires & 158.5 \\
\hline $\begin{array}{l}\mathrm{TiO}_{2} \text { nanofibers and nanowires after } \\
\text { calcination at 500 }{ }^{\circ} \mathrm{C} \text { for 2 } \mathrm{h}\end{array}$ & 125.1 \\
\hline $\begin{array}{l}\mathrm{TiO}_{2} \text { nanofibers and nanowires after } 24 \mathrm{~h} \\
\text { stirring in } 1 \mathrm{M} \mathrm{HCl} \text { and calcination at } 500{ }^{\circ} \mathrm{C} \\
\text { for 2 } \mathrm{h}\end{array}$ & 85.5 \\
\hline $\mathrm{Pure} \mathrm{TiO}_{2}+1.22 \%$ Pt nanofibers & 122.6 \\
\hline $\begin{array}{l}\mathrm{TiO}_{2}+1.22 \% \mathrm{Pt} \text { nanofibers calcinated at } \\
500{ }^{\circ} \mathrm{C} \text { for } 2 \mathrm{~h}\end{array}$ & 70.3 \\
\hline $\begin{array}{l}\mathrm{TiO}_{2}+6.27 \% \mathrm{Pt} \text { nanotubes calcinated at } \\
500{ }^{\circ} \mathrm{C} \text { for } 2 \mathrm{~h}\end{array}$ & 53.5 \\
\hline
\end{tabular}

The phase composition was determined by using $\mathrm{X}$ ray diffraction analysis with D8 Advance, Bruker AXS system. All samples were calcinated in $500{ }^{\circ} \mathrm{C}$ for $2 \mathrm{~h}$ to crystallise amorphous $\mathrm{TiO}_{2}$ before XRD analysis. XRD patterns of prepared samples showed anatase peaks and small amount $\mathrm{TiO}_{2}$ with monocline base centred structure indicating that $\mathrm{TiO}_{2}$ nanofibers and nanowires were still a bit X-ray amorphous. All XRD patterns of the calcinated samples were similar and beside intensive peaks exhibited also weak peak of amorphous phase (Fig. 1). Influence of $\mathrm{Pt}$ as dopant on phase composition were well shown in diffraction spectra of sample doped with $6.27 \%$ Pt. Diffraction spectrum of sample doped with $1.22 \% \mathrm{Pt}$ was without Pt peaks. It could be explained with detection limit of system. No other shifts of the diffraction peaks were observed.

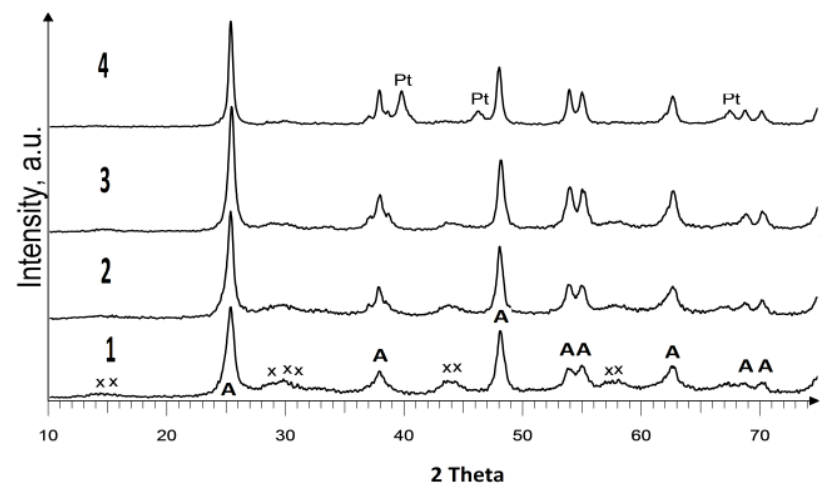

A-ANATASE; Pt-Platinum; $X-\mathrm{TiO}_{2}$ monoclinic, base-centred

Fig. 1. XRD patterns of the calcinated $\mathrm{TiO}_{2}$ nanofiber samples: pure $\mathrm{TiO}_{2}$ nanofibers and nanowires (1); $\mathrm{TiO}_{2}$ nanofibers and nanowires after stirring $24 \mathrm{~h}$ in $1 \mathrm{M} \mathrm{HCl}(2) ; \mathrm{TiO}_{2}$ nanofibers and nanowires doped with $1.22 \%$ platinum (3) and $\mathrm{TiO}_{2}$ nanofibers and nanowires doped with $6.27 \%$ platinum

Morphological characterization of prepared $\mathrm{TiO}_{2}$ samples were carried out by scanning electron microscope FE SEM MiralLMU, Tescan. SEM images are shown in Fig. 2. It is well shown that $\mathrm{TiO}_{2}$ nanofiber aglomerates containing from large amount of individual nanowires where obtained in the microwave synthesis process. Homogeneous individual nanowires were with diameters from $10 \mathrm{~nm}$ and with length more than $15 \mu \mathrm{m}$. 


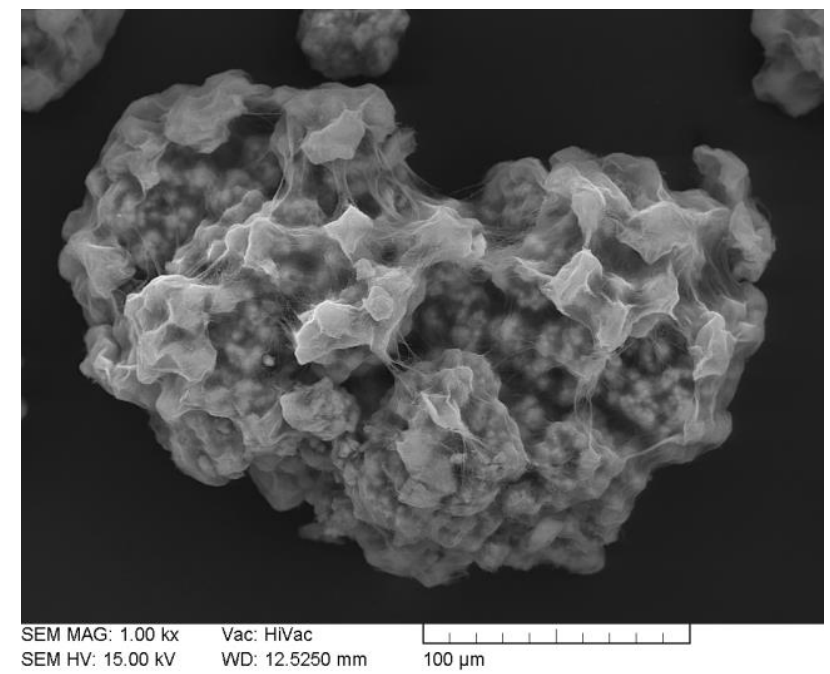

a

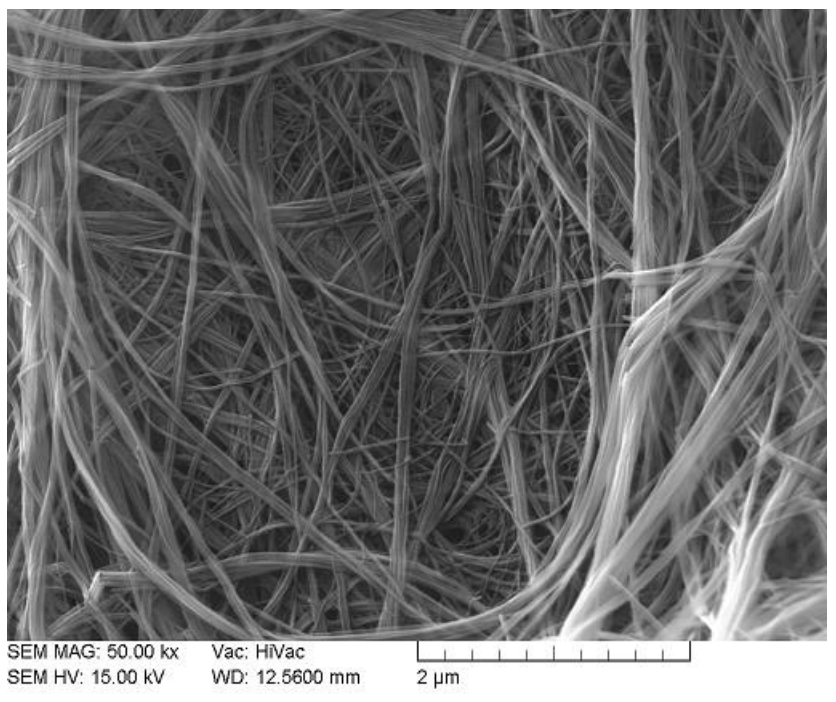

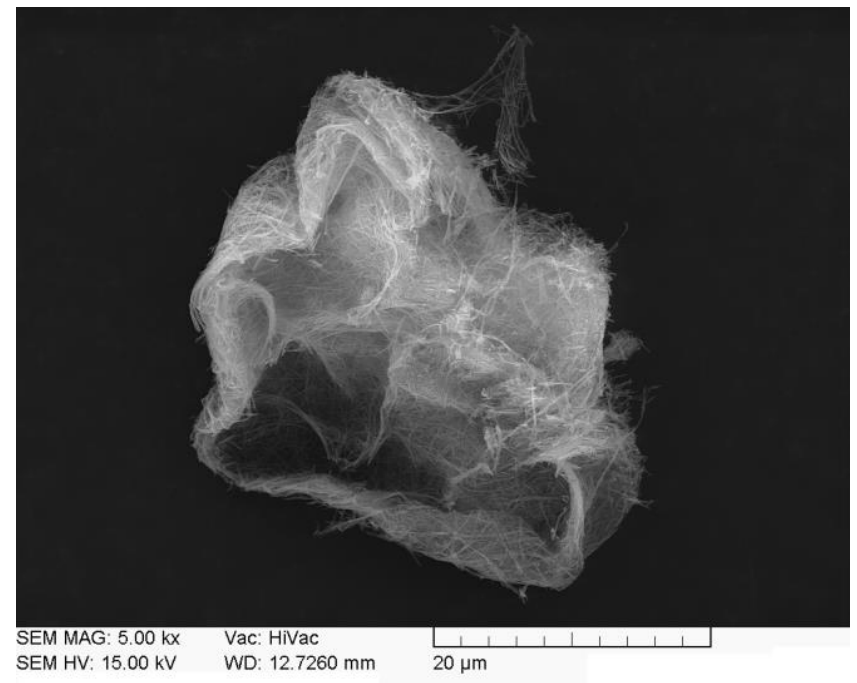

b

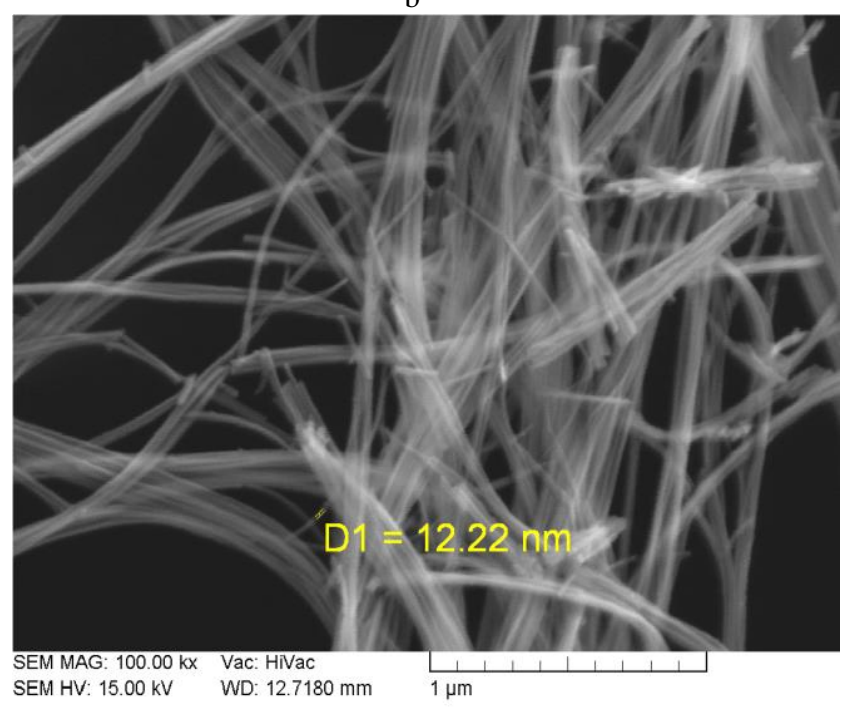

d

Fig. 2. SEM images of Pt-doped $\mathrm{TiO}_{2}$ nanofibers and nanowires under various magnification levels: $\mathrm{a}-1000 \mathrm{x} ; \mathrm{b}-5000 \mathrm{x} ; \mathrm{c}-50$ 000x; d - $100000 x$

Photocatalytical activity was measured in UV and VIS light irradiation. As pure $\mathrm{TiO}_{2}$ nanofibers and nanowires after microwave assisted synthesis were with extremely high specific surface area, there was a problem with high absorption of $\mathrm{MB}$ on $\mathrm{TiO}_{2}$ photocatalysts surface. It was noticed that already in stirring process in dark up to $95 \%$ of MB was absorbed on catalysts surface and nanopowder was blue while solution transparent. To fix this problem samples were stirred in $1 \mathrm{M} \mathrm{HCl}$ for $24 \mathrm{~h}$. After this procedure no absorption on catalysts surface while stirring in the dark were obtained and nanopowder was still white or light brown (for $\mathrm{TiO}_{2}$ sample containing $6.22 \% \mathrm{Pt}$ ) after $\mathrm{MB}$ degradation measurements. The pure $\mathrm{TiO}_{2}$ nanofibers and nanowires degraded about $58 \%$ of MB during $20 \mathrm{~min}$ under UV radiation. Prepared Pt- doped $\mathrm{TiO}_{2}$ photocatalysts had with up to $30 \%$ higher activity with respect to pure $\mathrm{TiO}_{2}$ nanofiber and nanowire powder. It was degraded up to $87 \% \mathrm{MB}$ after $20 \mathrm{~min}$ under UV irradiation (Fig. 3). Sample with only $1.22 \%$ Pt content had about $7 \%$ greater activity than sample containing $6.27 \% \mathrm{Pt}$ in UV irradiation. Under visible light irradiation the activity of prepared photocatalysts was much lower
(Fig. 4). Only about $11.5 \% \mathrm{MB}$ were degradated in 270 min experiment with sample contining $1.22 \% \mathrm{Pt}$ and about $6.5 \%$ in experiment with sample containing $6.27 \% \mathrm{Pt}$.

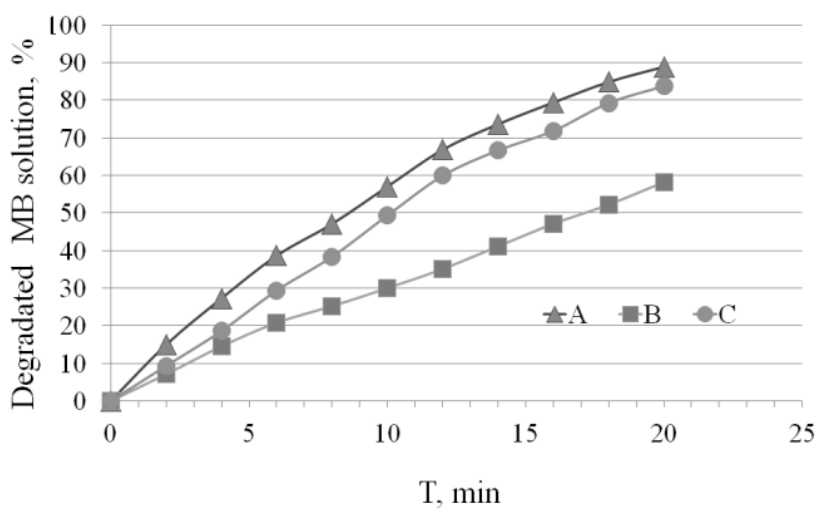

Fig. 3. Degradation of MB solution under UV irradiation: pure $\mathrm{TiO}_{2}$ nanofibers and nanowires (B); $\mathrm{TiO}_{2}-1.22 \% \mathrm{Pt}$ nanofibers and nanowires (A) and $\mathrm{TiO}_{2}-6.27 \% \mathrm{Pt}$ nanofibers and nanowires $(\mathrm{C})$ 
Activity of pure $\mathrm{TiO}_{2}$ nanofiber and nanowire photocatalysts in visible light was close to zero. Also after measurements under visible light photocatalysts were white or light brown (for $\mathrm{TiO}_{2}$ sample containing $6.27 \% \mathrm{Pt}$ ). The reason of this difference could be explained by unsufficient activity of the photocatalysts and by different radiation intensity.

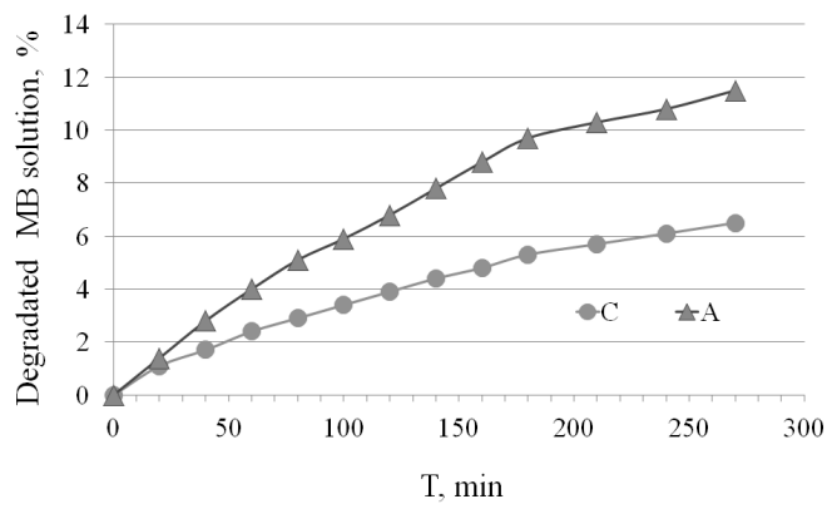

Fig. 4. Degradation of MB solution under visible light irradiation: $\mathrm{TiO}_{2}-1.22 \% \mathrm{Pt}$ nanofibers and nanowires (A) and $\mathrm{TiO}_{2}-6.27 \% \mathrm{Pt}$ nanofibers and nanowires $(\mathrm{C})$

Comparing results with literature it was notice that $\mathrm{Pt}$ doped nanofibers are with 20 to $30 \%$ higher photocatalytic activity in UV irradiation than $\mathrm{Pt}$ doped $\mathrm{TiO}_{2}$ nanotubes Literature data for photocatalytic activity of Pt doped $\mathrm{TiO}_{2}$ nanotubes under visible light irradiation should be examined critically because it is shown that the activity for pure $\mathrm{TiO}_{2}$ nanotubes under visible light is already $12 \%$ while it is well known that pure $\mathrm{TiO}_{2}$ is active only under UV irradiation [9].

\section{CONCLUSIONS}

Platinum doped $\mathrm{TiO}_{2}$ nanofibers and nanowires were successfully fabricated through a simple microwave treatment of the $\mathrm{TiO}_{2}$ anatase nanopowder. Obtained pure nanofibers and nanowires have specific surface area up to $158 \mathrm{~m}^{2} / \mathrm{g}$ and up to $122 \mathrm{~m}^{2} / \mathrm{g}$ when doped with $\mathrm{Pt}$. Individual anatase nanowires were with diameter from $10 \mathrm{~nm}$ and lenght up to $15 \mu \mathrm{m}$. Platinum doping can effectively enhance the photoelectrocatalytic activity of $\mathrm{TiO}_{2}$ under UV and visible-light irradiation. The highest photocatalytic activity of $\mathrm{Pt}$-doped $\mathrm{TiO}_{2}$ nanofibers and nanowires were shown by sample containing $1.22 \% \mathrm{Pt}$. Modification with platinum allows increase photocatalytic activity of $\mathrm{TiO}_{2}$ nanofibers and nanowires up to $30 \%$ under UV irradiation and up to $11.5 \%$ under visible light irradiation.

\section{Acknowledgments}

The financial support of government research program IMIS $^{2}$ in material science is greatly acknowledged.

\section{REFERENCES}

1. Drunka, R., Grabis, J., Jankovica, Dz., Patmalnieks, A. Preparation and Photocatalytic Activity of Doped $\mathrm{TiO}_{2}$ Nanotubes Latvian Journal of Chemistry 3/4 2011: pp. $250-255$.

2. Hashimoto, K., Irie, H., Fujishima, A. $\quad \mathrm{TiO}_{2}$ Photocatalysis: A Historical Overview and Future Prospects Japanese Journal of Applied Physics 12 (44) 2005: pp. 8269-8285.

3. Jitputti, J., Pavasupree, S., Suzuki, Y., Yoshikawa, S. Synthesis of $\mathrm{TiO}_{2}$ Nanotubes and its Photocatalytic Activity for $\mathrm{H}_{2}$ Evolution Japanese Journal of Applied Physics 47 2008: pp. $751-754$. http://dx.doi.org/10.1143/JJAP.47.751

4. Li, L., Qin, X., Wang, G., Qi, L., Du, G., Hu, Z. Synthesis of Anatase $\mathrm{TiO}_{2}$ Nanowires by Modifying $\mathrm{TiO}_{2}$ Nanoparticles Using the Microwave Heating Method Applied Surface Science 257 2011: pp. 8006-8012.

5. Yuan, B., Wang, Y., Bian, H., Shen. T., Wu, Y., Chen, Z. Nitrogen Doped $\mathrm{TiO}_{2}$ Nanotube Arrays with High Photoelectrochemical Activity for Photocatalytic Applications Applied Surface Science 280 2013: pp. 523-529.

6. Lv, J., Sheng, T., Su, L., Xu, G., Wang, D., Zheng, Z., Wu, Y. N,S Co-doped-TiO $2 /$ fly Ash Beads Composite Material and Visible Light Photocatalytic Activity Applied Surface Science 284 2013: pp. 229-234.

7. Yang, L., Xiao, Y., Liu, S., Li, Y., Cai, Q., Luo, S., Zeng, G. Photocatalytic Reduction of $\mathrm{Cr}$ (VI) on $\mathrm{WO}_{3}$ Doped Long $\mathrm{TiO}_{2}$ Nanotube Arrays in the Presence of Citric Acid Applied Catalysis B: Environmental 94 2010: pp. $142-149$.

8. Huang, H., Sun, C., Liu, L. Pt/N-codoped $\mathrm{TiO}_{2}$ Nanotubes and its Photocatalytic Activity under Visible Light Applied Surface Science 253 2007: pp. 7029-7035. http://dx.doi.org/10.1016/j.apsusc.2007.02.048

9. Su, Y., Deng, Y. Effect of Structure on the Photocatalytic Activity of Pt-doped $\mathrm{TiO}_{2}$ Nanotubes Applied Surface Science 257 2011: pp 9791-9795. http://dx.doi.org/10.1016/j.apsusc.2011.05.133

10. An'Amt, N., Radiman, S., Huang, M., Yarmo, A., Ariyanto, P., Lim, N., Muhamed, R. Sol-gel Hydrothermal Synthesis of Bismuth- $\mathrm{TiO}_{2}$ Nanocubes For Dye-sensitized Solarcell Ceramics International 36 2010: pp. $2215-2220$. http://dx.doi.org/10.1016/j.ceramint.2010.05.027

11. Luo, Q., Cai, Q., Li, M., Chen, X. Characterization and Photocatalytic Activity of Large-Area Single Crystalline Anatase $\mathrm{TiO}_{2}$ Nanotube Films Hydrothermal Syntized on Plasma Electrolytic Oxidation Seed Layers Journal of Alloys and Compounds 597 2014: pp.101-109. 